\title{
LA ESCUELA EN LA CONSTRUCCIÓN DE LA IDENTIDAD SOCIOCULTURAL DE LA LOCALIDAD
}

María De Castro Zumeta y Rosmel Orfila Vilera
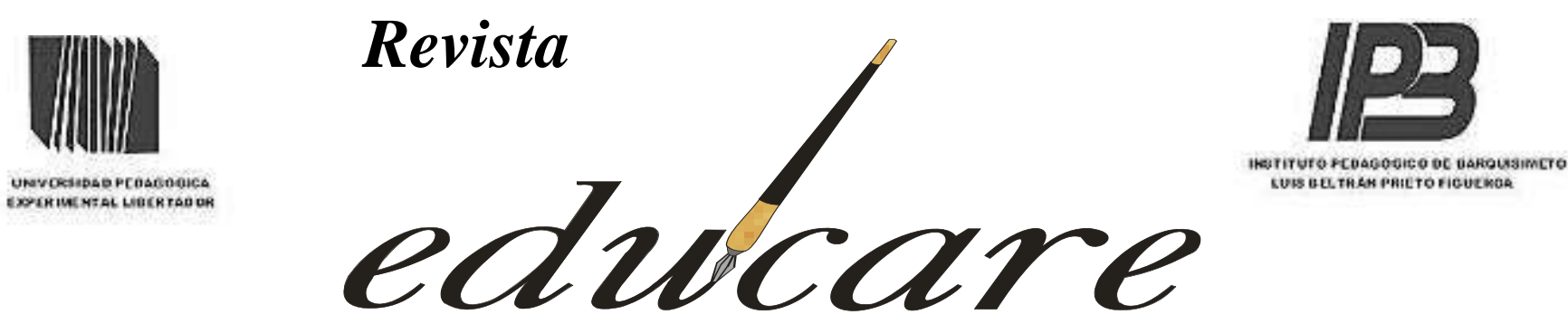

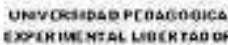

Órgano Divulgativo de la Subdirección de Investigación y Postgrado

del Instituto Pedagógico de Barquisimeto "Luis Beltrán Prieto

Figueroa"

Barquisimeto Estado Lara

Venezuela

\section{Volumen 23 № 3 Septiembre-Diciembre 2019}

\section{LA ESCUELA EN LA CONSTRUCCIÓN DE LA IDENTIDAD SOCIOCULTURAL DE} LA LOCALIDAD

THE SCHOOL IN THE CONSTRUCTION OF THE SOCIOCULTURAL IDENTITY OF THE LOCALITY

\section{S S N : $2244-7296$}

\author{
Autor \\ María De Castro Zumeta \\ Rosmel Orfila Vilera \\ Universidad de Carabobo (UC) \\ Venezuela
}




\section{LA ESCUELA EN LA CONSTRUCCIÓN DE LA IDENTIDAD SOCIOCULTURAL DE LA LOCALIDAD \\ María De Castro Zumeta y Rosmel Orfila Vilera}

(pp.110-131)

\section{Revisión Documental}

Recibido: 20-03-2019

\section{RESUMEN}

La escuela en la construcción de la identidad sociocultural de la localidad fue el tema central de la revisión documental que se presenta a continuación. Se analizaron diversos autores para acercarse a la comprensión de los mecanismos psicosociales e históricos que contribuyen en la construcción de la identidad sociocultural de una localidad. La conciencia individual y colectiva, las raíces históricas, las imágenes de sí mismo de los individuos y del grupo, el entorno geohistórico local, las manifestaciones de la cultura, la institución escolar, la familia, los patrones culturales foráneos, entre otros, componen el fermentum de la identidad sociocultural, donde la escuela se ha convertido en un referente clave. Finalmente, se concluye que todos los individuos y el grupo en su conjunto son constructores de la identidad sociocultural de la localidad pero es la escuela la cultivadora de la misma.

Descriptores: Identidad sociocultural; escuela; localidad.
*María De Castro Zumeta

**Rosmel Orfila Vilera

Universidad de Carabobo Aceptado:23-09-2019

\begin{abstract}
The school in the construction of the sociocultural identity of the town was the central theme of the documentary review presented below. Several authors were analysed to draw closer to understanding the psychosocial and historical mechanisms that contribute to the construction of a locality's sociocultural identity. Individual and collective consciousness, historical roots, selfimages of individuals and groups, local geohistorical environment, manifestations of culture, school institution, family, foreign cultural patterns, among others, they make up the fermentum of sociocultural identity, where school has become a key benchmark. Finally, it is concluded that all individuals and the group as a whole are builders of the sociocultural identity of the locality but is the school that is the grower of the same
\end{abstract}

Key words: Sociocultural identity; school; Locality

*María De Castro Zumeta. Doctora en Educación. Profesora Titular. Universidad de Carabobo. Facultad de Ciencias de la Educación. Departamento de Ciencias Pedagógicas. Valencia Edo. Carabobo. Coordinadora del Grupo de Investigación para la Reflexión Educativa (GIRE). Línea de Investigación: Escuela, Comunidad y Gerenciahttps://orcid.org/0000-0001-7857-618X Correo electrónico: marias36@ hotmail.com

**Rosmel Orfila Vilera. Doctor en Educación. Profesor Titular. Universidad de Carabobo. Facultad de Ciencias de la Salud. Escuela de Salud Pública y Desarrollo Social. Departamento de Ciencias Sociales. Valencia Edo. Carabobo. Correo electrónico: rosmel.orfila.vilera@gmail.com

Volumen 23, N³, Septiembre-Diciembre 2019. ISSN 2244-7296 


\section{LA ESCUELA EN LA CONSTRUCCIÓN DE LA IDENTIDAD SOCIOCULTURAL DE LA LOCALIDAD \\ María De Castro Zumeta y Rosmel Orfila Vilera}

(pp.110-131)

\section{Introducción}

Abordar la influencia de la escuela en el proceso de construcción de la identidad sociocultural de una localidad, invita a la reflexión, debate y cuestionamiento de diversas perspectivas teóricas, tendentes a interpretar la naturaleza de la misma. La identidad sociocultural de una localidad se percibe, siente y representa en el modo de vida de los individuos organizados en grupos donde se desenvuelven y perpetuán la memoria histórica. La gente, asentada en un entorno geohistórico determinado, va configurándose una idea de sí mismo, consustanciado en un imaginario que le es propio y que imprime patrones de comportamientos culturales genuinos: una lengua, manifestaciones populares sui generis como danza, música, gastronomía, creencias religiosas, gestos, en fin toda una simbología digna de ser mirada desde las subjetividades de cada individuo.

Importa dirigir la atención a la escuela, institución social que coadyuva en el aseguramiento vital de los patrones socioculturales del acervo cultural local. Para tener una idea clara en torno al rol protagónico de la institución escolar en la conformación de la identidad sociocultural local, se hace necesario considerar la escuela como espacio de ejercicio en el tejido de los lazos sociales que se aspira tener. En ella, como micro espacio de la realidad se interpreta y reinterpreta el cosmos social, hacerlo desde lo simbólico sería una manera distinta porque debido a la larga hegemonía de lo empírico-racionalista en la elaboración del conocimiento se imposibilita llegar al mismo si no es a través de la lógica tradicional, en este escenario el símbolo, la imaginación, lo imaginario y las representaciones eran rechazadas como fuentes de conocimiento.

En la socialización del sujeto, la palabra cotidianidad, las rutinas, las costumbres, los actos repetitivos realizados con internalización y conciencia crean representaciones y símbolos de valores que hacen distinguir al sujeto como individuo pero también como parte de un grupo. Estas continuas representaciones permiten reproducir la herencia cultural del grupo. De allí, la importancia social atribuida a la institución escolar, lo que es obligante para la misma valorar respuestas a interrogantes como: ¿Es suficiente un docente con alta preparación

Volumen 23, $N^{\circ} 3$, Septiembre-Diciembre 2019. ISSN 2244-7296 


\section{LA ESCUELA EN LA CONSTRUCCIÓN DE LA IDENTIDAD SOCIOCULTURAL DE LA LOCALIDAD \\ María De Castro Zumeta y Rosmel Orfila Vilera}

(pp.110-131)

académica y comprometido con el ejercicio de su profesión para contribuir en la construcción del proceso de formación de la identidad sociocultural del niño? ¿Cómo crear escenarios pedagógicos en el aula que se vinculen con el entorno geohistórico local? ¿Qué hacer para despertar el interés y motivación de los estudiantes para que amen su propia cultura, la internalicen y la respeten?, planteamientos a considerar como ejes fundantes de un curriculum escolar que consolide la visión de asegurar la preservación de la identidad sociocultural de la localidad.

\section{Referentes y Perspectivas Teóricas para Abordar y Comprender la Identidad Sociocultural}

"Culturas e identidades son representaciones simbólicas socialmente construidas, y no legados pasivamente heredados"

Mato (1993)

Abordar la identidad sociocultural de una localidad cualquiera brinda la posibilidad de irrumpir en los ricos escenarios de elementos y facetas dimensionales que le dan fisonomía, aprehendiendo de esta manera su naturaleza y dinámica en el tránsito histórico hasta lograr apreciarse los rasgos que la manifiestan. Al estar circunscrita en un contexto históricoespacial, la identidad sociocultural se va construyendo y consolidando progresivamente en la medida que la acción antrópica, ésta es la de los seres humanos, de manera consciente e inconsciente, va aportando elementos culturales al grupo y al espacio dibujándole unos rasgos característicos únicos los cuales se traducen en su identidad propia.

La identidad es un proceso que se construye, se va fraguando en la misma medida en que actúan aportaciones de cada individuo y de las instituciones culturales como la familia y la escuela, entre otros de vital importancia en esta materia. La construcción de la identidad sociocultural es un producto del pensar, actuar y expresar simbólicamente el "mundo de vida" del grupo humano en un espacio geohistórico determinado. Es decir, se comparte la aseveraciones de Velásquez (2005), al citar a Geertz quien deja por sentado al referirse a la cultura, a la identidad y los seres humanos en sociedad, "que el análisis de la cultura ha de

Volumen 23, $N^{\circ} 3$, Septiembre-Diciembre 2019. ISSN 2244-7296 


\section{LA ESCUELA EN LA CONSTRUCCIÓN DE LA IDENTIDAD SOCIOCULTURAL DE \\ LA LOCALIDAD \\ María De Castro Zumeta y Rosmel Orfila Vilera}

(pp.110-131)

ser, por tanto, no una ciencia experimental en busca de leyes, sino una ciencia interpretativa en busca de significaciones" (p.20).

Lógicamente, si de lo que se trata es de estudiar a los seres humanos y, con éste, sus obras como constructor de identidades socioculturales, es decisivo acercarse a los mismos con la firme intención de comprender su acervo cultural, interpretando con ello los diversos elementos dimensionales que la componen: identidad, símbolos, usos, costumbres, hábitos, lenguaje, entre otros. Por tratarse de una concepción/perspectiva subjetiva, a continuación se muestra un cuadro-síntesis que ilustra algunos productos conceptuales y teóricos, generados por tres científicos sociales, con respecto al constructo identidad sociocultural, los cuales permitirán un panorama acerca de su naturaleza y dinámica:

\section{Cuadro 1}

Matriz de definiciones y perspectivas teóricas acerca de la identidad sociocultural

\begin{tabular}{|c|c|c|c|}
\hline & Montero (2008) & Mosonyi (1981) & García (1993) \\
\hline 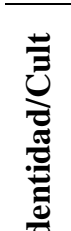 & $\begin{array}{l}\text { La identidad es la } \\
\text { representación del ser, } \\
\text { expresada en la imagen que } \\
\text { como grupo humano posee de } \\
\text { sí mismo. (p. 16) }\end{array}$ & $\begin{array}{l}\text { La cultura se refugia en la } \\
\text { memoria del grupo y del } \\
\text { hombre. (p. 8) }\end{array}$ & $\begin{array}{l}\text { La identidad alude a los } \\
\text { procesos y valores simbólicos } \\
\text { compartidos colectivamente,... } \\
\text { (p. 28) }\end{array}$ \\
\hline
\end{tabular}

\begin{tabular}{|c|c|c|c|}
\hline 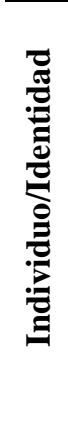 & $\begin{array}{l}\text { Permite a los individuos } \\
\text { reconocerse socialmente como } \\
\text { miembros de un grupo. (p. } 76 \text { ) }\end{array}$ & $\begin{array}{l}\text { Todos los pueblos, grandes } \\
\text { o pequeños, tienen una historia } \\
\text { y en esa historia todos ellos se } \\
\text { transforman. (p. } 49 \text { ) }\end{array}$ & $\begin{array}{l}\text { Cada individuo es } \\
\text { representante de una sociedad, } \\
\text { y a su vez es sujeto y actor de } \\
\text { una compleja cadena de una } \\
\text { relación social. Para entender } \\
\text { una expresión, hay que conocer } \\
\text { la lengua; para comprender el } \\
\text { comportamiento de una } \\
\text { persona hay que conocer su } \\
\text { medio cultural, específico, } \\
\text { particular. (p. } 27 \text { ) }\end{array}$ \\
\hline
\end{tabular}




\section{LA ESCUELA EN LA CONSTRUCCIÓN DE LA IDENTIDAD SOCIOCULTURAL DE \\ LA LOCALIDAD \\ María De Castro Zumeta y Rosmel Orfila Vilera}

(pp.110-131)

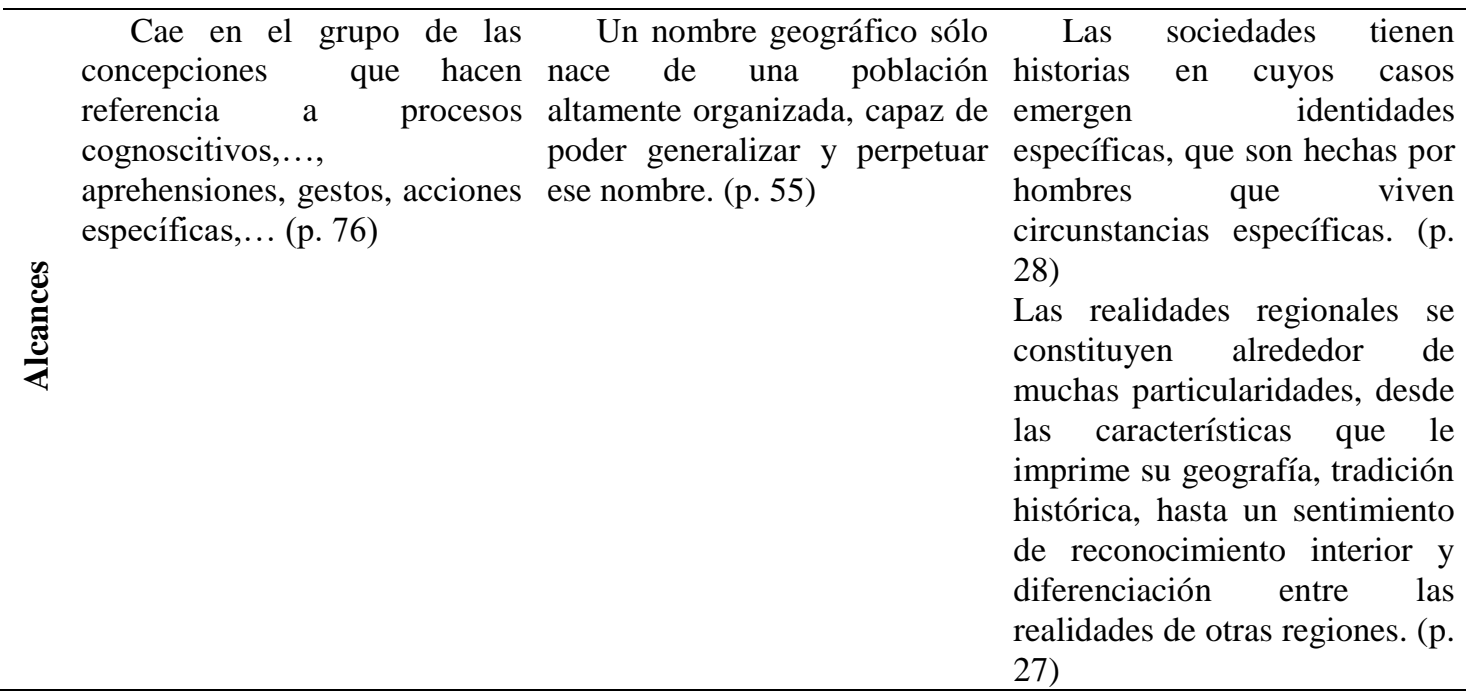

El

aborado por Orfila y De Castro (2019)

Mosonyi (1981), García (1993) y Montero (2008), coinciden en que la identidad sociocultural se asocia a un ser humano que hace vida en un espacio y que a través de su relación con otros seres va tejiendo su memoria, lo cual permite, indudablemente, comprenderla y apreciar la magnitud del alcance de la misma para entender los procesos vitales de una localidad, pueblo, Nación e inclusive contextos regionales macro geográficos como a nivel continental. Así que, como lo advierte Ricoeur (2008), "comprender no es ya entonces un modo de conocimiento, sino más bien un modo de ser, el modo de ser del ser que existe al comprender" (p. 13), con lo que queda entendido que el mismo individuo que hurga su entorno local, parroquial o micro espacio en el cual habita al tratar de comprender su identidad es partícipe en su construcción y al mismo tiempo parte íntegra de la misma, prolongándola de manera directa al grupo humano y a su descendencia progresivamente en un continuum inexorable.

La identidad sociocultural de una localidad se nutre, en forma lenta pero progresiva, de las representaciones de cada individuo y del grupo en su conjunto: imágenes que poseen de sí mismos, memoria histórica consustanciada en episodios puntuales, diversidad cultural

Volumen 23, $N^{\circ} 3$, Septiembre-Diciembre 2019. ISSN 2244-7296 


\section{LA ESCUELA EN LA CONSTRUCCIÓN DE LA IDENTIDAD SOCIOCULTURAL DE LA LOCALIDAD \\ María De Castro Zumeta y Rosmel Orfila Vilera}

(pp.110-131)

asimilada de otras latitudes, sentimientos de reconocimiento con grupos organizados, procesos cognoscitivos; los cuales imprimen rasgos definitorios a los patrones socioculturales de valores, símbolos, gestos, lengua, expresiones y manifestaciones artísticas como música, danza, cuento, leyenda, mito, fábula, novela, entre otros. Estos elementos dimensionales, representan lo que E. Husserl, retomado por Ricoeur (op cit) denomina Lebenswelt o el "mundo de la vida" (p. 13), mundo éste que se construye con el poderoso referente de la identidad sociocultural de cualquier entorno geohistórico determinado, acepción de indiscutible valor para comprender y compenetrarse con la identidad de un grupo.

Como queda esclarecido a través de las anteriores consideraciones teóricas y perspectivas de análisis asumidas, no cabe duda alguna que la identidad, de acuerdo a Garza y Llanos (2015), se construye y "es el producto de una triple adaptación en los hombres que se produce en los planos biológico, afectivo y mental" ( $\mathrm{s} / \mathrm{p}$ ), por ello se quiere estudiar a la institución Escuela como protagonista decisiva en generar aportes socioculturales que de manera progresiva consolidan y prolongan la identidad de cualquier localidad.

\section{La Escuela, el Resguardo del Acervo Cultural y la Identidad Sociocultural}

"A través de la enseñanza de la historia y la tradición, va a recibir el niño la concepción y valoración de la trayectoria espacio-tiempo, que su pueblo ha cumplido, es decir, la historia de sí mismo, su identidad" Velásquez (1993)

La escuela, como una de las instituciones socioculturales preminentes de la sociedad, es quizás la segunda en importancia y con poder formativo después de la institución familia, a través de la cual la socialización se ha convertido en una dimensión posibilista para asegurar la asimilación, permanencia y la transmisión de la cultura. En concordancia con éste último aspecto indicado, González (1993), hace especial énfasis en que "uno de los mecanismos más importantes para la transmisión de la tradición y la construcción de identidades es el sistema

Volumen 23, N³, Septiembre-Diciembre 2019. ISSN 2244-7296 


\section{LA ESCUELA EN LA CONSTRUCCIÓN DE LA IDENTIDAD SOCIOCULTURAL DE LA LOCALIDAD \\ María De Castro Zumeta y Rosmel Orfila Vilera}

(pp.110-131)

de educación formal" (p. 53), reiterándose de esta manera que la escuela es una institución encargada de resguardar el acervo cultural presente en el imaginario colectivo de la localidad en la cual impacta directamente. Además, configura prácticas de socialización que permiten la construcción progresiva de la identidad sociocultural de cada niño y grupo en general. Pero esto lleva a reflexionar con relación a la afirmación de Hernández (2002), quien advierte que "hay que recuperar al estudiante como un sujeto social, rechazando a la persona como una entidad abstracta" (s/p). Hace un llamado el autor a potenciar en el sujeto en formación su mundo social, que se construye en la unión de la conciencia y la acción, proceso en el cual podría el imaginario colectivo tener un papel importante en la construcción de la identidad sociocultural.

Durante el arqueo heurístico de distintas fuentes, se condensaron aportaciones singulares que le imprimen valor sustancial al status y rol de la institución escolar en el reguardo de la memoria histórica y, por consiguiente, en la construcción de la identidad sociocultural. Uno de tales productos es el de Martínez y Muñoz (2009), de la Universidad de Manizales (Colombia), quienes exponen que los imaginarios sociales son construcciones culturales afectadas por la temporalidad, expresándose de formas diversas de acuerdo al contexto social, pero estos autores reconocen en los imaginarios sociales una forma de memoria colectiva que penetra desde el conocimiento más científico hasta las expresiones culturales más simples de la vida cotidiana, lo que permite guiar la acción humana y darle sentido. El tener un norte que guie la vida cotidiana con sentido podría ser interpretado como un concepto de cohesión social.

Por otra parte, cabe destacar que durante el progresivo proceso de construcción de la identidad sociocultural intervienen diversos elementos que la van complementando y posibilitando la identidad como tal, así como se tiene la diferenciación entre el concepto y las características entre representaciones colectivas que formuló en su momento Emile Durkheim y las representaciones colectivas de Moscovici son desarrolladas en parte por el trabajo de Álvarez (2011), de la Universidad de Antioquia (Colombia). En su reflexión la

Volumen 23, $N^{\circ} 3$, Septiembre-Diciembre 2019. ISSN 2244-7296 


\section{LA ESCUELA EN LA CONSTRUCCIÓN DE LA IDENTIDAD SOCIOCULTURAL DE LA LOCALIDAD \\ María De Castro Zumeta y Rosmel Orfila Vilera}

(pp.110-131)

autora señala que el concepto de representaciones sociales de Durkheim es concebido como forma de conciencia que la sociedad le imprime al individuo como una reproducción de la idea social; mientras que, en el concepto de representaciones sociales de Moscovici, las formas de conciencia son generadas por los sujetos sociales como producción y elaboración de carácter social. Desde esta perspectiva, la autora asume la sociedad no como una imposición externa sino como un campo de resignificaciones entre los sujetos y sus relaciones.

Así que, la conciencia individual y de grupo ha sido un poderoso factor para la "reproducción de la idea de sociedad", por tanto le imprime una impronta, una huella poderosa que trae consigo el fraguado de la identidad sociocultural. Y parte sustancial de éste proceso cognoscitivo se va perfilando y nutriendo dentro de la institución escolar. Este último fundamento de ideas expuestos, refuerzan la perspectiva de que en la escuela se produce -interpretando a Álvarez- procesos de constantes resignificación en los cuales se va configurando la identidad sociocultural del sujeto en formación.

En concordancia con lo anterior, Redón (2010), de la Universidad Católica de Valparaíso (Chile), plantea que la escuela es un espacio de formación ciudadana. La catedrática se plantea interrogantes como ¿Qué imaginarios construyen [los niños y las niñas] de la vida colectiva en la que están inmersos la mayor parte de su tiempo-vital?, ¿Qué cultura construye la escuela como espacio de formación ciudadana? Desde estas interrogantes, la cultura escolar es definida por Redón (2010),

como el conjunto de prácticas y simbolizaciones construidas en la escuela, [que] se encuentra hoy afectada predominantemente por el cruce de dos culturas; una asociada al tradicionalismo controlador reproducido por el propio sistema educativo y otra emergente vinculada a la cultura social que promueve un individualismo que repercute en la forma de mirar a los otros y al mundo. (p. 235).

Se trata de un problema bastante complejo, y en el caso de la realidad venezolana más aún. En la escuela gravitan muchos actores involucrados: además de los básicos, estudiantes y docentes, se encuentra toda una comunidad cargada de representaciones y símbolos que

Volumen 23, $N^{\circ} 3$, Septiembre-Diciembre 2019. ISSN 2244-7296 


\section{LA ESCUELA EN LA CONSTRUCCIÓN DE LA IDENTIDAD SOCIOCULTURAL DE LA LOCALIDAD \\ María De Castro Zumeta y Rosmel Orfila Vilera}

(pp.110-131)

forman un segundo grupo que hace vida en la escuela y forma parte de la cultura escolar. Este segundo grupo de actores serían: la familia (padres, representantes y responsables), personal (administrativo, de ambiente, madres cocineras) a lo cual se suma la presencia cada vez más notoria de los Consejos Comunales. Este segundo grupo pudiera ser interpretado siguiendo a Redón- como una cultura social emergente. Esta postura lleva a indagar en los marcos éticos, políticos y sociales presentes en todos los involucrados en el proceso escolar.

\section{La Construcción de la Identidad y sus Escenarios}

"La identidad como proceso que se construye y desarrolla en la interacción con los grupos de referencia; familia, comunidad escolar, vecinal, étnica, regional, nacional, incorpora la construcción de la personalidad, la historia, la cultura; por cuanto los grupos de referencia son portadores y transmisores de la cultura, la cual trasciende el lapso cronológico de la vida individual"

Velásquez (1993)

Desde el punto de vista de las perspectivas antropológica, sociológica, psicológica, histórica y educativa, coexisten enfoques que tienden a reiterar que la identidad sociocultural no se construye en el vacío, en la nada. En cada individuo, en cada grupo y en cada sociedad convive y eclosiona los elementos que la conforman: raíces históricas que arrastras vestigios de culturas milenarias desde las precolombinas hasta las provenientes de remotas latitudes donde se han nutrido, a su vez, de aquellas formaciones pasadas propias del hombre primitivo, hasta llegar a enriquecerse de los rasgos e identidades actuales consustanciadas en las inexorables olas mundializadoras - como las llama Edgar Morín- como lo son los medios de comunicación de masas, la Web, redes sociales digitales, entre otros.

Al respecto, es interesante resaltar que la cultura ha sido la clave interpretativa para comprender el proceso de construcción de la identidad sociocultural de una localidad, donde las instituciones sociales fundamentales: familia, escuela, religión, entre otras, juegan un papel decisivo en la misma. Para Velásquez (1993)

Volumen 23, $N^{\circ} 3$, Septiembre-Diciembre 2019. ISSN 2244-7296 


\section{LA ESCUELA EN LA CONSTRUCCIÓN DE LA IDENTIDAD SOCIOCULTURAL DE \\ LA LOCALIDAD \\ María De Castro Zumeta y Rosmel Orfila Vilera}

(pp.110-131)

La cultura impone normas, también usos y costumbres, sistemas religiosos, asimismo, existen circunstancias históricas como también signos y símbolos culturales que nos identifican pero cada quien asume su "identidad" de acuerdo a sus particularidades y diferencias frente a los demás. (p. 87)

Otras perspectivas explicativas guardan coincidencia con Velásquez (1993), como lo constituye los aportes de Nicolás (2007), quien hace especial énfasis en que la identidad es un asunto de construcción social con significación cultural, siendo la identidad social producto de la historia, de la socialización (p. 16). La anterior afirmación se sustente en teóricos como Schütz (1989) y Berger y Luckman (1966). Schütz (1989) incorpora el mundo de la vida cotidiana, dimensión ontológica también compartida y difundida por E. Husserl, con lo que abre la posibilidad de estudiar los sistemas e instituciones y las relaciones cara a cara, pudiéndose valorar el conjunto de relaciones interpersonales y las actitudes de la gente, sus patrones aprendidos y la forma en que son reproducidos en la vida cotidiana.

En Chile, existe la experiencia presentada a través del informe de la Comisión Nacional de Formación Ciudadana (2004) de un estudio realizado que recuerda que "el sistema escolar es la institución mediante la cual la sociedad perpetúa su propia existencia”, para lo cual cada sujeto debe visualizarse dentro de un proyecto común donde se comprometan en el presente, recogiendo la memoria histórica y mirando hacia un futuro común.

El informe de la Comisión reconoce en el sistema escolar al encargado de la reproducción de una generación a otra, donde los sentimientos y creencias que la cohesionan es vital para alcanzar la ciudadanía. En este proceso la identidad es fundamental. En otro estudio Redón (2012), define la identidad como el "cimiento que subyace a un proyecto común y como dialéctica permanente social-personal en la vida de los sujetos, cuya <<morada>> o espacio de lo común $<<$ institucionalizado $>>$ se denomina escuela".

Por otra parte, Cegarra (2010) afirma que las representaciones sociales son precodificaciones porque codifican un conjunto de anticipaciones y expectativas, es decir, el individuo debe tener una experiencia previa que le imprimirá esa representación, he allí lo

Volumen 23, $N^{\circ} 3$, Septiembre-Diciembre 2019. ISSN 2244-7296 


\section{LA ESCUELA EN LA CONSTRUCCIÓN DE LA IDENTIDAD SOCIOCULTURAL DE LA LOCALIDAD \\ María De Castro Zumeta y Rosmel Orfila Vilera}

(pp.110-131)

subjetivo; lo colectivo será porque esa representación dependerá de la sociedad en la cual vive, pues eso medirá la forma de vivirla, actuarla y representarla.

Desde esta perspectiva teórica Aubeterre (2012) aborda el estudio de la realidad social local, asumiendo como principio que ésta se construye desde las prácticas sociales cotidianas de: las personas, las organizaciones sociales (sindicatos, Consejos Comunales, clubes, partidos políticos, empresas, ONG's, asociaciones profesionales, gremios, redes sociales (Facebook, Twitter, entre otros), las instituciones del Estado y los medios de comunicación social. Es decir, de todo eso que ahora se llama los actores sociales, participantes en el juego socio-político que caracteriza la memoria histórica de un país, colectivo humano, pueblo o etnia.

En este sentido, Marañón (2011), plantea que

La memoria histórica es un recuerdo colectivo, una evocación volcada hacia el presente del valor simbólico de las acciones colectivas vividas por un pueblo en el pasado. Es una acción que preserva la identidad y la continuidad de un pueblo, es no olvidar lo aprendido, muchas veces con sangre, es el camino para no repetir errores pasados. La memoria es un hecho transformado en sistema de valores. $(\mathrm{s} / \mathrm{p})$.

La memoria histórica es guardar, mantener, conservar, transmitir y difundir la memoria, no son actos puramente conservadores en el sentido profundo de la palabra, por el contrario, son actos necesarios para pensar el cambio y hacerlo posible, que significa, entre otras cosas, la construcción de identidades o el refuerzo de las mismas, reflejado en el sentido de pertenencia a un grupo social, uno de los grandes dilemas de hoy.

\section{Identidad Socio-Cultural, Escuela y Localidad}

“Cultura,..., condición de conjunto de prácticas simbólicas de representación y valoración del mundo, compartida por los integrantes de un grupo humano. Se trata de una perspectiva desde la cual la cultura no es percibida como una esencia inmutable, sino más

bien como una estrategia de integración del grupo con su entorno"

Fernández (2005)

Volumen 23, $N^{\circ} 3$, Septiembre-Diciembre 2019. ISSN 2244-7296 


\section{LA ESCUELA EN LA CONSTRUCCIÓN DE LA IDENTIDAD SOCIOCULTURAL DE LA LOCALIDAD \\ María De Castro Zumeta y Rosmel Orfila Vilera}

(pp.110-131)

La construcción de la identidad socio-cultural de un entorno geohistórico local es el producto de la confluencia de la acción antrópica, la memoria histórica, las instituciones sociales como la escuela y las inmensas posibilidades que brinda el espacio de servir de asentamiento de los grupos humanos diversos, por eso para Araujo (2017) "la escuela como centro de formación no tiene solo la función de transmitir conocimientos sino además de proteger el acervo socio-cultural, promover valores y saberes de identidad, integrando a la comunidad como fuente de sabiduría para enriquecer la praxis pedagógica" (p. 316).

Así, cabe destacar que esta construcción parece estar más vinculada a la Historia Regional y Local. Al respecto, asevera Guinand (2010), aun cuando se trata de una crónica, en uno de sus trabajos de Naguanagua en el estado Carabobo que "algunas escuelitas de principios del siglo pasado aún persisten en la memoria de quienes las conocieron" (p. 79). Cabe preguntar: ¿Qué es lo que hace que persista en la memoria ciertas instituciones educativas? ¿Persiste solo en la memoria individual o también en la memoria colectiva? ¿Es parte del imaginario colectivo algunas escuelas? ¿Es parte de su construcción como localidad? Otro aporte congruente con Guinand (2010), se encuentra con la contribución de Guánchez (2005), en su crónica, donde expresa aspectos históricos, geográficos, religiosos y educativos entre otros de Marín en el estado Yaracuy.

En esta obra el capítulo titulado "Instituciones Educativas" se hace un recorrido por la fundación de varias de ellas, pero llama la atención que al referirse a sus docentes lo hace de la manera siguiente el autor: "algunos docentes recordados con mucho afecto por la comunidad son: (....)". "Este querido plantel, como pionero de la educación (...)” (p. 30 y 31). Con relación a estas remembranzas y evocaciones cabe preguntar: ¿Qué le hace ser un “querido plantel” para la comunidad? ¿Es parte del imaginario colectivo? ¿Por qué recuerdan con "afecto" a los docentes?

Dichos sentimientos cargados de estima al evocar antañas instituciones escolares e insignes docentes de las mismas y que aun sus recuerdos están inalterables en la memoria histórica, alude a las huellas históricas imborrables que aun sobreviven en la conciencia

Volumen 23, $N^{\circ} 3$, Septiembre-Diciembre 2019. ISSN 2244-7296 


\section{LA ESCUELA EN LA CONSTRUCCIÓN DE LA IDENTIDAD SOCIOCULTURAL DE LA LOCALIDAD \\ María De Castro Zumeta y Rosmel Orfila Vilera}

(pp.110-131)

individual y colectiva de muchas personas. Este fenómeno en particular ha sido abordado por Lorenz y Morín, retomado por Fernández (2005), quien expone lo siguiente:

Un hito importante en la génesis de la perspectiva teórica sobre la dinámica socio-cultural se deriva de su encuentro con la obra de Konrad Lorenz. En efecto, Lorenz fue el primero en proponer, desde el terreno de la etología, el concepto de impronta para referirse a la huella imborrable que dejan las primeras experiencias de la vida en la memoria del animal joven.... De acuerdo con Morin,..., existiría también en la especie humana una impronta cultural, que se fijaría en la memoria desde el nacimiento, con los valores y representaciones esenciales transmitidos al sujeto por la familia, la escuela, y en su vida adulta. (p. 21).

Haciendo un ejercicio de reflexión e interpretación de lo esbozado hasta aquí, se parte de la idea que la realidad educativa es cambiante y es parte de la construcción social del sujeto y del grupo organizado, donde se pretende dar continuidad intergeneracional a lo establecido, lo cual se inscribe en el mecanismo integrador de cada sujeto. La problematización de la identidad sociocultural del escolar implica un proceso de búsqueda de autonomía dentro de un marco de relaciones interdependientes y procesuales de la escuela tomando en cuenta la intersubjetividad.

Las principales interrogantes que surgen sobre los mecanismos psicosociales y socioculturales decisivos en la construcción de la identidad sociocultural apuntan a la búsqueda de respuesta a cuestiones temáticas como: ¿Qué se construye? ¿Cómo se construye? ¿Quiénes construyen? Con relación a estas interrogantes, u otras más que bien pueden establecerse como orientadoras de estudio, se reitera que la identidad es un asunto de construcción social, con significación cultural y en la cohesión social de una localidad cuya esencia es la preservación de su memoria histórica. Se ratifica una vez más la perspectiva teórica que enfatiza que la identidad brinda la posibilidad de ser construida, retroalimentada, diversificada y proyectada a otros individuos y grupos, pues, como lo advierte Montero (2008):

La identidad nacional sería también una de las formas de expresión de la identidad social, construida por los individuos en función de otros individuos, basada en elementos socioculturales compartidos y formando parte de un sistema

Volumen 23, $N^{\circ} 3$, Septiembre-Diciembre 2019. ISSN 2244-7296 


\section{LA ESCUELA EN LA CONSTRUCCIÓN DE LA IDENTIDAD SOCIOCULTURAL DE \\ LA LOCALIDAD \\ María De Castro Zumeta y Rosmel Orfila Vilera}

(pp.110-131)

de representaciones del cual la imagen nacional sería una de sus expresiones.... Con carácter relativamente permanente y de proceso ya que la identidad ni es fija ni es estática. Cambia, evoluciona, se transforma, generando siempre un núcleo fundamental que permite el reconocimiento del sí mismo colectivo (p. 77)

Con preocupación se escucha constantemente entre educadores y padres, madres, representantes o responsables de los estudiantes expresiones clave como "la escuela ya no es la misma", "la escuela no es como antes" y entre los "nosotros" se comenta con insistencia "en mis tiempos.... No éramos así” donde se observa una ruptura generacional entre el hoy y el ayer, y esto a pesar de los esfuerzos realizados por la instituciones escolares, sus docentes, y directivos por desarrollar estrategias psicopedagógicas y de trabajo de aula escolar destinadas a crear escenarios creativos para involucrar a toda la comunidad escolar dentro de los procesos propios del acervo patrimonial sociocultural de la localidad, a través de un curriculum que trasciende las aulas de clase y dirigiéndose hacia contextos más locales y regionales donde anida la esencia cultural por excelencia, necesaria para la construcción de una genuina identidad sociocultural que los diferencie de los otros.

En este sentido, se comprende en los actuales momentos la presencia de un sentir colectivo no ideal, el cual permite inferir que hay un antes y un ahora con respecto a la preeminencia en la función formadora de la escuela de hoy. Esta discrepancia podría estar haciendo perder la memoria histórica de la institución escolar y de la localidad en la cual hace vida, perdiéndose progresivamente las raíces propias de la historicidad e idiosincrasia de la localidad al olvidarse la historia pequeña vinculada a sentimientos de pertenencia al terruño, con sus manifestaciones populares como la música, danzas, cuentos, leyendas, mitos, gastronomía, lengua, entre otros elementos, ocasionados por la irrupción de patrones extraños, provenientes de culturas foráneas a través de procesos de aculturación y transculturación y de procesos sociohistórico como es el caso de los anclajes (amarre de tradiciones, símbolos, pautas de comportamientos, lengua, entre otros, que un individuo o grupo arrastra consigo una vez que abandona su lugar de origen y lo sigue proyectando en el nuevo lugar de asentamiento) y su consecuente reinstauración de pautas y comportamientos

Volumen 23, $N^{\circ} 3$, Septiembre-Diciembre 2019. ISSN 2244-7296 


\section{LA ESCUELA EN LA CONSTRUCCIÓN DE LA IDENTIDAD SOCIOCULTURAL DE LA LOCALIDAD \\ María De Castro Zumeta y Rosmel Orfila Vilera}

(pp.110-131)

productos de los movimientos migracionales, como claramente lo ha expresado Mosonyi (1981).

Por estas consideraciones expuestas es que las instituciones escolares, la familia como célula fundamental de la sociedad, los testimonios vivientes, el patrimonio cultural tangible e intangible, el espacio geohistórico, son los factores clave que, al decir de García (1993):

Luchan por la supervivencia de sus miembros, reafirmando una identidad cultural o determinadas raíces históricas,..., como una postura que se identifica con lo local, con lo propio, como punto de partida para impulsar desarrollos consustanciados con sus realidades, preservando su identidad, valorando sus recursos naturales y evitando alejarse de su historicidad e idiosincrasia... El espacio no constituye un receptáculo dentro del cual tienen lugar los procesos sociales, sino que, es parte del proceso de reproducción social por el que cada formación se produce históricamente. Es el producto histórico de una sociedad, al mismo tiempo que es parte determinante de los procesos sociales. (p.p. 31 y 32)

Considerando los argumentos de la autora precitada, también pueden ser formuladas en torno a ¿Qué pasaría si la institución escolar no incluye entre las competencias que quiere alcanzar en el estudiantado el desarrollo progresivo de la identidad sociocultural? ¿Cuáles serían las consecuencia de que los escolares en sus primeros años de escuela no se les oriente a percibir y sentir la identidad sociocultural de su localidad? ¿Cómo serían los patrones de comportamiento, lengua y cultura de los infantes, jóvenes y adolescentes si desconocen sus raíces históricas? ¿Se impondría entonces una identidad sociocultural foránea enriqueciéndose y fraguándose hasta lograr borrar la memoria histórica vernácula? Teniendo en consideración estas interrogantes, se estaría en presencia de una verdadera hipertrofia en materia de identidad sociocultural local y nacional, pues de ser así, como lo advierte Velásquez (1993)

Se afirma que gran parte de los seres humanos responde a códigos falsos con los cuales se identifica. Esto conlleva descaracterización y una identidad que no tiene asidero orgánico ni psicológico. Sólo trae desarraigo y vergüenza étnica. Solamente comprendiendo las especificidades culturales podemos hablar de construcción de identidades. (p. 85)

Volumen 23, $N^{\circ} 3$, Septiembre-Diciembre 2019. ISSN 2244-7296 


\section{LA ESCUELA EN LA CONSTRUCCIÓN DE LA IDENTIDAD SOCIOCULTURAL DE LA LOCALIDAD \\ María De Castro Zumeta y Rosmel Orfila Vilera}

(pp.110-131)

Así, la escuela, los docentes, estudiantes, familias y comunidad local en general deben ser consciente del papel protagónico que juegan en la construcción de la identidad sociocultural, asegurándole su vigencia en la memoria colectiva, revalorizando las raíces históricas remotas reviviéndolas en el imaginario social, nutriéndola a su vez de los nuevos componentes socioculturales que van emergiendo producto del contacto y simbiosis con otros individuos, grupos e identidades diversas, pero manteniendo la esencia como tal.

\section{Reflexiones Finales}

Los planteamientos desarrollados permiten perfilar una perspectiva lo suficientemente amplia como para comprender la naturaleza y dinámica de la identidad sociocultural de una localidad y, en la misma, comprender el papel decisivo de la escuela, de los docentes y de los estudiantes lo que invita a reflexionar al respecto tomando como base algunas interrogantes que dirijan la mirada hacia esclarecer los factores clave de dicho proceso educativo: ¿Cómo entiende la escuela primaria, en su práctica pedagógica, la formación de la identidad sociocultural de los escolares desde tempranas edades? ¿Cómo se establece en la escuela primaria las acciones que apunten hacia la cohesión social? ¿De qué manera se construye el imaginario colectivo de lo común, desde la escuela primaria, para la preservación de la memoria histórica? ¿Cómo es vista la escuela por su localidad en la cual está inmersa? ¿Qué elementos identifican los estudiantes de la escuela primaria como parte de su identidad sociocultural tanto individual así también como integrantes de un grupo?

La escuela ha tenido históricamente un status y rol preferencial en todas las sociedades de la humanidad toda vez que después de la institución familiar, y los demás mecanismos culturales que posibilitan la cohesión social, ha influenciado en gran medida en la consolidación de las bases socioculturales que sirven de ejes maestros en la construcción, consolidación y perpetuación de las identidades en cada uno de los entornos geohistóricos donde la presencia humana es la nota dominante por excelencia.

Volumen 23, $N^{\circ} 3$, Septiembre-Diciembre 2019. ISSN 2244-7296 


\section{LA ESCUELA EN LA CONSTRUCCIÓN DE LA IDENTIDAD SOCIOCULTURAL DE LA LOCALIDAD \\ María De Castro Zumeta y Rosmel Orfila Vilera}

(pp.110-131)

Como genuina componente de la cultura, la escuela es considerada un agente modelador de patrones de comportamientos tan necesarios para asegurar la vida en sociedad, posibilitando la transmisión del acervo histórico, por una parte, y del legado humanístico y tecnológico, por la otra, los cuales conforman los ejes dimensionales del curriculum escolar del sistema educativo. De éste último, la identidad sociocultural se enriquece al ser parte íntegra y necesaria de las áreas de aprendizaje de los pensum de estudios, desde los primeros niveles de la escolaridad formal infantil hasta los estudios de bachillerato y universitarios.

No cabe la menor duda de que la identidad sociocultural se va construyendo progresivamente y de manera inexorables, y durante su proceso de consolidación se va transformando, incorporando -a través de una simbiosis- los nuevos aportes de las instituciones sociales, de la escuela, y, lógicamente, de cada uno de los individuos y del grupo en su conjunto. Se forma de esta manera la imagen que todos tienen de sí mismos pero también de los demás, como producto de un proceso enmarcado en el relacionamiento de los factores cognoscitivos, históricos, geográficos, culturales, sociales y educativos.

La identidad sociocultural es permeable, recibe plácidamente los aportes de los grupos humanos fundadores de cada localidad geohistórica, así como también de los provenientes de otras latitudes disímiles, incorporándole substratos ideales y no ideales que pasan a forman parte íntegra del tronco esencial de la identidad sociocultural vernácula. En este último escenario, la asimilación espontánea de patrones extraños puede distorsionar progresivamente la esencia de la identidad sociocultural genuina, tal como así ocurre, por ejemplo, con la intromisión y usos compartidos de neologismos, modas cargadas de vicios, costumbres y hábitos alienantes, entre otros elementos degenerativos de la idiosincrasia.

Concebida la identidad sociocultural como proceso en construcción, la institución escolar debe tener muy en consideración mirar detenidamente su visión y misión, especialmente cuando se trata de velar para contrarrestar la penetración de patrones socioculturales no ideales que atentan contra la idiosincrasia local-regional-nacional, y que los escolares de las primeras edades fácilmente tienden a asimilarlos como suyos.

Volumen 23, $N^{\circ} 3$, Septiembre-Diciembre 2019. ISSN 2244-7296 


\section{LA ESCUELA EN LA CONSTRUCCIÓN DE LA IDENTIDAD SOCIOCULTURAL DE LA LOCALIDAD \\ María De Castro Zumeta y Rosmel Orfila Vilera}

(pp.110-131)

Se asume que la identidad sociocultural local y la escuela guardan estrecha relación con la historia local-regional, la conciencia histórica y el imaginario colectivo que se tiene de sí mismo los individuos y el grupo, el terruño y el afecto/amor hacia lo propio que se convierten en actitudes de apego a "lo propio", y que se comporte con los otros en un rico escenario de pedagogía social orquestado desde la escuela y la familia.

Los docentes de aulas en las escuelas tienen en sus manos la posibilidad y la oportunidad de contribuir, a través de sus aportes, a incentivar la curiosidad y el espíritu inquisidor de los educandos hacia los contextos dimensionales propios de la identidad sociocultural local, y una de las manera de influencia más ideal y eficaz es a través del ejemplo. Por ello, cada docente de aula debe tener conciencia histórica y social, tener definido el don de la docencia y, a su vez, poseer una concepción ideal y necesaria de sus raíces históricas y culturales del entorno geohistórico donde vive y se desarrolla académicamente como docente de aula.

Docentes de aula que no posean conciencia histórica, de su status y rol social y carezcan de conocimientos de su propia historia e identidad, se convierten en sujetos que atentan contra la esencia de la institución escolar, trayendo consigo el debilitamiento de las bases de la identidad sociocultural. Sin embargo, es bueno recordar que los especialistas en Cultura vienen realizando esfuerzos dentro de las escuelas para rescatar la memoria histórica de lo local, pasando por lo regional y llegando a lo nacional, para lo cual se hace necesario el apoyo de todos los miembros que conforman la comunidad escolar tales como padres, representantes, personal administrativo y de ambiente, así como de miembros de la comunidad, esos patrimonios vivientes que están impregnados de conocimiento de un acervo cultural presente, vivo, que debe ser preservado por todos.

\section{Referencias}

Álvarez R., N. (2011). Las representaciones sociales: una ruta posible para formar maestros intelectuales de Ciencias Sociales. [Artículo en línea]. Disponible: http://aprendeenlinea.udea.edu.co/revistas/index.php.unip/issue. [Consulta: 2018, Marzo 15]

Volumen 23, $N^{\circ} 3$, Septiembre-Diciembre 2019. ISSN 2244-7296 


\section{LA ESCUELA EN LA CONSTRUCCIÓN DE LA IDENTIDAD SOCIOCULTURAL DE LA LOCALIDAD \\ María De Castro Zumeta y Rosmel Orfila Vilera}

(pp.110-131)

Araujo A., J. (2017). Integración de los saberes comunitarios como estrategia de aprendizaje en la praxis educativa de la comunidad escolar los Llanitos de Timotes. [Artículo en línea]. Disponible: http://indteca.com/ojs/index.php/Revista_Scientific/article/view/106. [Consulta: 2019, Octubre 22]

Aubeterre, L. (2012). Imaginario colectivo, sentido común e identidades sociales: triángulo reflexivo sobre la construcción social de la realidad cotidiana y las organizaciones de los ciudadanos. [Artículo en línea]. Disponible: http://guayanaweb.ucab.edu.ve/tl_files/ciepv/foro_guayana_sustentable/ponencias/p articipacion_social/Percepciones\%20sobre\%201a\%20participacion\%20social.pdf [Consulta: 2019, Enero 08]

Berger, Peter y Luckman, Thomas (1966). La construcción de la realidad social. [En línea]. Disponible: .ve/\#sclient=psy-ab\&q=Theaproximaci\%C3\%B3n+ teorica+ método logica+al+imaginario+social+y+las+representaciones+colectivas [Consulta: 2019, Enero 08]

Cegarra, J. (2012). Fundamentos Teórico Epistemológicos de los Imaginarios Sociales. [Artículo en línea]. Disponible: http:// www.moebio.uchile.cl/43/ cegarra.html. [Consulta: 2018, Noviembre 23]

Fernández C., Gustavo. (2005). La patria imaginaria: Bases para una etnocrítica de la cultura Latinoamericana. En: Globalización y multiculturalismo. (2005). Mérida, Marco T., Fernández C., Gustavo y Machado, Franklin (Compiladores). Valencia: Universidad de Carabobo. Consejo de Desarrollo Científico y Humanístico de la Universidad de Carabobo.

García, Ilia. (1993). Análisis regional e identidades regionales. En: Diversidad cultural y construcción de identidades. Estudios sobre Venezuela, América Latina y el Caribe. (1993). Daniel Mato (Coordinador). Caracas: Tropykos. Centro de Estudios Postdoctorales. Facultad de Ciencias Económicas y Sociales, Universidad Central de Venezuela.

Garza L., E. y Llanos A., H. (2015). Modelo pedagógico para desarrollar la identidad cultural. [Artículo en línea]. Disponible: http://scielo.sld.cu/scielo.php?script=sci_arttext\&pid=s1727-1202015000300011. [Consulta: 2019, Octubre 22]

Gonzáles O., Enrique A. (1993). Lo biocultural-binacional en expansión. En: Diversidad cultural y construcción de identidades. Estudios sobre Venezuela, América Latina y el Caribe. (1993). Daniel Mato (Coordinador). Caracas: Tropykos. Centro de Estudios

Volumen 23, $N^{\circ} 3$, Septiembre-Diciembre 2019. ISSN 2244-7296 


\section{LA ESCUELA EN LA CONSTRUCCIÓN DE LA IDENTIDAD SOCIOCULTURAL DE LA LOCALIDAD \\ María De Castro Zumeta y Rosmel Orfila Vilera}

(pp.110-131)

Postdoctorales. Facultad de Ciencias Económicas y Sociales, Universidad Central de Venezuela.

Guanchez, O. (2005). Marín...Un pueblo yaracuyano. Valencia: T.B. Print, C.A.

Guinand, C. (2010). Naguanagua. La Begoña. Valencia: Cosmográfica, C.A.

Hernández C., G. (Febrero-Marzo 2002). El imaginario educativo de la comunicación, hacia una conciencia participativa. [Artículo en línea]. Disponible: http://www.razonypalabra.org.mx/anteriores/n25/ghernan.html. [Consulta: 2018, Diciembre 03]

Marañón R., J. (Mayo, 2011). Reflexiones teóricas acerca de la interrelación entre memoria histórica e imaginarios sociales. [Artículo en línea]. Disponible: http:// www.eumed.net/rev/cccss/12/.[Consulta: 2018, Noviembre 13]

Martínez P., J. y Muñoz G., D. (2009). Aproximación teórico-metodológica al imaginario social y las representaciones colectivas: apuntes para una comprensión sociológica de la imagen. [Artículo en línea]. Disponible: http://revistasjaverianas.edu.com. [Consulta: 2018, Noviembre 25]

Mato, Daniel. (1993). Construcción de identidades pannacionales y transnacionales en tiempos de globalización: Consideraciones teóricas y sobre el caso de América Latina. En: Diversidad cultural y construcción de identidades. Estudios sobre Venezuela, América Latina y el Caribe. (1993). Daniel Mato (Coordinador). Caracas: Tropykos. Centro de Estudios Postdoctorales. Facultad de Ciencias Económicas y Sociales, Universidad Central de Venezuela.

Montero, Maritza. (2008). Ideología, alienación e identidad nacional. Caracas: Universidad Central de Venezuela.

Mosonyi, Esteban E. (1981). Identidad nacional y culturas populares. Caracas: La Enseñanza Viva.

Nicolás C., S. (Agosto, 2007). De la leyenda al mito. La narrativa en la construcción de la identidad profesional de la enfermera. [Artículo en línea]. http://www.uaeh.edu.mx/docencia/Tesis/icschu/doctorado/documentos/De\%201a\%201 eyenda\%20al20mito.pdf. [Consulta: 2018, Noviembre 25]

Redón P., S. (2010). La escuela como espacio de ciudadanía. [Artículo en línea]. http://polis.revues.org/2367. [Consulta: 2018, Noviembre 25]

Volumen 23, $N^{\circ} 3$, Septiembre-Diciembre 2019. ISSN 2244-7296 


\section{LA ESCUELA EN LA CONSTRUCCIÓN DE LA IDENTIDAD SOCIOCULTURAL DE LA LOCALIDAD \\ María De Castro Zumeta y Rosmel Orfila Vilera}

(pp.110-131)

Redón P., S. (2012). Escuela e identidad: un desafío docente para la cohesión social. [Artículo en línea]. http://polis.revues.org/2367. [Consulta: 2018, Diciembre 11]

Ricoeur, Paul. (2008). El conflicto de las interpretaciones. Ensayo sobre Hermenéutica. México: Fondo de Cultura Económica.

Schütz, Alfred. (1989). La construcción significativa del mundo social. Barcelona: Paidos.

Velásquez, Janette. (2005). Cultura y Tecnología ¿Origen o incertidumbre de la globalización cultural? En: Globalización y multiculturalismo. (2005). Mérida, Marco T., Fernández C., Gustavo y Machado, Franklin (Compiladores). Valencia: Universidad de Carabobo. Consejo de Desarrollo Científico y Humanístico de la Universidad de Carabobo.

Velásquez, Rony. (1993). Venezuela pluriétnica: el otro y la diferencia, el mito y las identidades. En: Diversidad cultural y construcción de identidades. Estudios sobre Venezuela, América Latina y el Caribe. (1993). Daniel Mato (Coordinador). Caracas: Tropykos. Centro de Estudios Postdoctorales. Facultad de Ciencias Económicas y Sociales, Universidad Central de Venezuela.

Volumen 23, $N^{\circ} 3$, Septiembre-Diciembre 2019. ISSN 2244-7296 